\title{
Analysis of URL References in ETDs: A Case Study at the University of North Texas
}

\author{
Mark Phillips \\ UNT Libraries \\ University of North Texas \\ Denton, Texas, USA
}

\author{
Daniel Gelaw Alemneh \\ UNT Libraries \\ University of North Texas \\ Denton, Texas, USA
}

\author{
Brenda Reyes Ayala \\ UNT Libraries \\ University of North Texas \\ Denton, Texas, USA
}

Keywords: Link Analysis, ETD, Electronic Theses and Dissertations, Link Extraction, Web Archiving

\section{Background}

Libraries have traditionally been responsible for collecting and curating the research needed by graduate students and faculty to complete their scholarly activities, and in turn, they work to acquire this completed scholarly literature in a virtuous-circle of building research collections around and for the research conducted at their institution. The number of scholarly Web resources is growing as movements such as Open Access allow and encourage researchers and scholars to publish their findings and research in non-traditional ways. The need to locally capture and curate these items is being raised in academic research libraries around the world. Whereas the library community has long standing workflows and processes for identifying, acquiring, and describing traditional scholarly literature, the Web has raised many new and unanswered questions about how to accomplish these same tasks for the online environment. By and large academic libraries are not capturing and maintaining collections of Web resources that provide context and historical reference points to the modern theses and dissertations held in their collections.

Recent work has looked at the persistence and availability of web resources referenced from papers in scholarly repositories. Sanderson, Phillips, and Van de Sompel (Sanderson et al., 2011) showed that $46 \%$ of URLs extracted from ETDs in the UNT Libraries ETD Collection were not archived by the international Web archiving community. The Sanderson study found that of the 17,965 unique URLs from the UNT ETD collection, only 54\% (9880) of the URLs were available in one or more archives with $28 \%$ (5073) that could not be automatically discovered as either still available or present in a Web archive.

While $54 \%$ of these URLs are resolvable in Web archives around the world, there is no direct statement of responsibility pertaining to the Web archives' commitment to maintaining these resources or their accessibility into the future. Further, this study looked at the existence of an instance of the referenced URL and its availability; this does not take into account that the archived version may not be the temporally correct version of the resource cited in the ETD. 
SalahEldeen and Nelson discuss this anomaly in their research in the area of temporal intention and its effect on Web archives. (SalahEldeen and Nelson 2013)

A recommendation of the Sanderson paper suggested that repositories should expose the list of URLs referenced in each paper using an API that could allow for the programmatic extraction and harvesting of these referenced URLs. Based on the recommendation, the UNT Libraries implemented an API that makes available extracted URLs from the full-text of a publication in the UNT Digital Library; this functionality can be viewed by appending urls.txt to the end of Archival Resource Key (ARK) identifier used by the UNT Digital Library. For example, as can be seen from Figures 1 and 2, the resource located at http://digital.library.unt.edu/ark:/67531/metadc155622/ can be queried for the URLs embedded in the full-text of the document at this URL http://digital.library.unt.edu/ark:/67531/metadc155622/urls.txt .

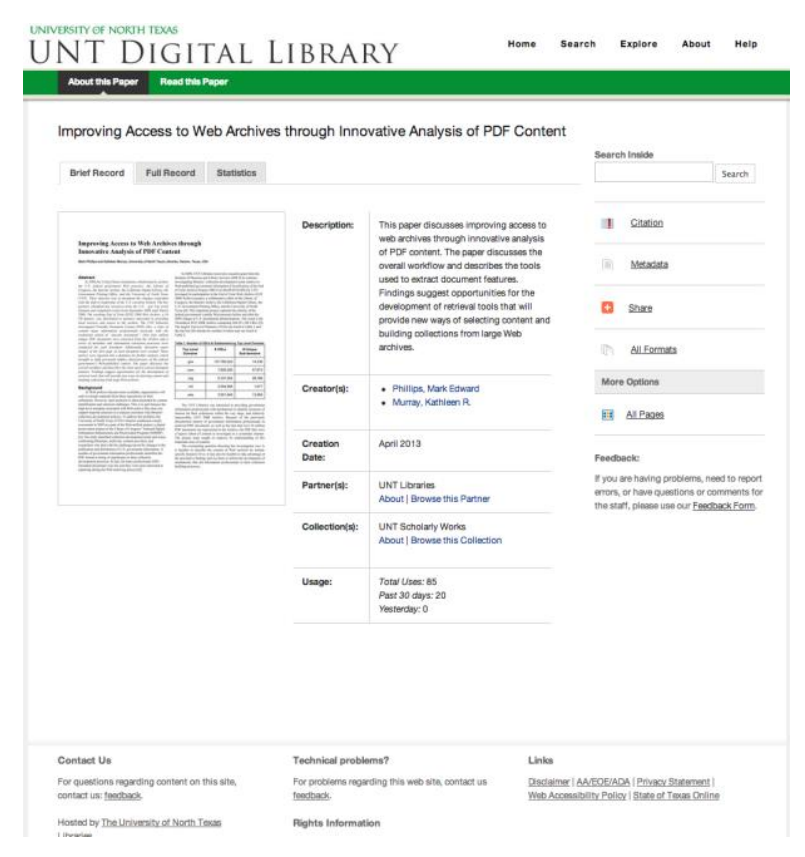

Figure-1: Sample document located at http://digital.library.unt.edu/ark:/67531/metad c155622/

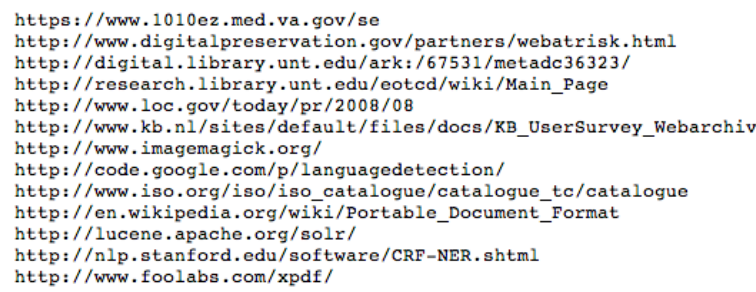

Figure-2: Sample URLS Embedded in the Document: http://digital.library.unt.edu/ark:/67531/metadc 155622/urls.txt

The authors are interested in how the Web is being utilized as both a subject and a vehicle for scholarly communication as represented in ETDs. By better understanding the linking patterns and uncovering their trends, the authors hope to present a more informed picture of overall URL references in the ETD collection in the UNT Digital Library and to reinforce the importance of this class of information resource and therefore the value in identifying, collecting and curating cited URLs and websites. 
The overarching research question directing this investigation was: How has the number and frequency of URLs cited in electronic theses and dissertations changed over the past decade in the UNT Libraries ETD Collection.

\section{Methods}

Essentially four steps were involved in this investigation. The first step was an investigation into a variety of link extraction methods popular in libraries and Web archiving in order to understand the challenges posed in the extraction of links from full-text documents. Next a set of processes was employed to extract a dataset of URLs and associated metadata from the UNT-ETD collection. The third step indexed the resulting dataset by a number of extracted elements and additional elements of interest. In the final step, queries were formulated to characterize the URL linking patterns contained in the dataset. (NOTE: Technical references at the end of the paper identify the URLs of the maintenance organizations for tools and standards included in this paper.)

\section{URL Extraction}

In order to extract URLs from the UNT-ETD corpus the authors decided to proceed with a workflow that emphasized the use of extracted full-text of the document instead of internal indication of what constituted a $U R L$ reference. The reasoning behind this is twofold, first there are many ways to reference an external URL in a PDF document. If this work were limited to URLs explicitly marked as external, a large portion of URLs might be missed because of the local typesetting and style guides used in the preparation of the ETDs. Second the URL extraction methods discussed here can be more widely used in the digital library environment if they are not based on a specific document format and structure.

To understand the URL linking practices present in ETDs, the authors chose a small sample dataset composed of 28 documents from UNT's ETD collection and then used a variety of methods to extract the links from each thesis or dissertation. In some cases, we extracted links from the PDF documents themselves, while in others we first converted the PDF file to text, and then ran the file extraction utilities. We used the following link extraction methods:

1. UNT's current implementation for extracting URLs from a publication.

2. A Python script created locally to test improved extraction methods (not discussed further in this paper).

3. An instance of the PDFParser module present in the Heritrix web crawler. This module takes PDF documents as inputs and then outputs a list of URIs present in the document (Internet Archive, 2012b).

4. An instance of the ExtractorUniversal module present in the Heritrix web crawler, slightly modified to allow it to process PDF files. This module is described as "A last ditch extractor that will look at the raw byte code and try to extract anything that looks like a link" (Internet Archive, 2012a).

5. A Linux utility called "urlview" that extracts URLs from text files (Elkins, n.d.). 
One of the authors manually processed each of the 28 theses and dissertations - extracting and tallying all URL candidates to serve as the "gold standard" or "ground truth" used to evaluate the URL extraction methods.

For this experiment, we used an open-ended definition of a URL reference. For instance, a link did not need to be preceded by "http://" or "www" to be considered as such. It also did not need to be present only in the bibliography section of the thesis or dissertation but rather could be part of the narrative text itself. Opting for a more open definition affected the results obtained during the link extraction process, as some extraction algorithms are quite rigid in defining a URL.

The results from this preliminary experiment are shown below. In information retrieval, precision is the percentage of retrieved documents that are relevant to the search, while recall, also called sensitivity, is the percentage of documents that are relevant to the query that are successfully retrieved. In this case,

Precision $=$ \# of correct links returned $/$ \# of results returned

Recall = \# of correct links returned / \# of links that should have been returned

\begin{tabular}{|l|l|l|}
\hline Link Extraction Method & $\begin{array}{l}\text { Average Precision } \\
\text { Measured (\%) }\end{array}$ & $\begin{array}{l}\text { Average Recall Measured } \\
(\%)\end{array}$ \\
\hline UNT's current service & $96.67 \%$ & $96.12 \%$ \\
\hline Python script (match.py) & $95.34 \%$ & $97.09 \%$ \\
\hline Heritrix PDFParser & $10.71 \%$ & $9.24 \%$ \\
\hline Heritrix ExtractorUniversal & $51.49 \%$ & $84.00 \%$ \\
\hline Linux “urlview" utility & $100.00 \%$ & $87.90 \%$ \\
\hline
\end{tabular}

$<$ Table-1: Link extraction method with average precision and recall measured $>$

As can be seen from Table-1, the UNT Library's current link extraction service and the Python script had the best overall performance, with Heritrix's PDFParser module performing the worst on the link extraction task.

While investigating URL extraction tools and software packages, the authors conducted a brief analysis into linking patterns in ETDs in order to better understand the way that URLs are cited and referenced in the document text. Below is a summary of the findings. 


\section{How URLs are represented in electronic theses and dissertations}

The process of extracting URLs from theses and dissertations might seem trivial at first glance, but it is more complicated in practice. In our sample dataset URLs were represented in a multitude of ways, which made the process of link extraction more difficult than it appeared to be. The following are some examples of ways URL references appear in UNT's electronic theses and dissertations:

\begin{tabular}{|c|c|c|}
\hline $\begin{array}{l}\text { URL } \\
\text { Category }\end{array}$ & Sample URL Referenced in the Text & Source \\
\hline $\begin{array}{l}\text { URL referenced in the } \\
\text { body of the text }\end{array}$ & $\begin{array}{l}\text { Although the ARG as a game genre has } \\
\text { emerged quite recently, Web sites such } \\
\text { as unfiction.com and ARGNet have links } \\
\text { to several past and current ARGs, such } \\
\text { as Cathy's Book and } \\
\text { iamtryingtobelieve.com. Some ARGs } \\
\text { have served a marketing function, such } \\
\text { as ilovebees.com that supported the } \\
\text { release of Microsoft's Halo } 2 \text { video game. }\end{array}$ & $\begin{array}{l}\text { (Dondlinger 2009, p. } \\
\text { 31) }\end{array}$ \\
\hline \multirow[t]{2}{*}{$\begin{array}{l}\text { URLs referenced in the } \\
\text { text with fuller references } \\
\text { included in the } \\
\text { bibliography }\end{array}$} & $\begin{array}{l}\text { Appendix C includes a copy of the final } \\
\text { questionnaire, which was administered } \\
\text { online using SurveyMonkey.com. }\end{array}$ & (Alemneh 2009, p. 75) \\
\hline & $\begin{array}{l}\text { To participate in this online survey please } \\
\text { go to: } \\
\text { http://www.surveymonkey.com/s.aspx?s } \\
\text { m=uehwFW92JN5NXfhpwFC8Cw 3d 3 } \\
\underline{d}\end{array}$ & $\begin{array}{l}\text { (Alemneh 2009, p. } \\
\text { 190). }\end{array}$ \\
\hline $\begin{array}{l}\text { URL used as the name of } \\
\text { the website in a } \\
\text { bibliographic reference }\end{array}$ & $\begin{array}{l}\text { [15] 52north.org, "52North Sensor Web”, } \\
\text { http://52north.org. }\end{array}$ & (Yang 2010, p. 94) \\
\hline
\end{tabular}




\begin{tabular}{|l|l|l|}
\hline \multirow{2}{*}{$\begin{array}{l}\text { DrugLibrary.org, } \\
\text { www.druglibrary.org/schaffer/hemp/histor } \\
\text { y/mistonij1.html, (accessed Feb. 16, } \\
\text { 2008) }\end{array}$} & (Liles 2008, p. 150) \\
\cline { 2 - 3 } $\begin{array}{l}\text { Spencer, J. (2001, October 11). Decoding } \\
\text { bin Laden. Newsweek.com [On-line]. } \\
\text { Available: } \\
\text { http://www.msnbc.com/news/641689.asp }\end{array}$ & (Horton 2002, p.135) \\
\hline $\begin{array}{l}\text { URL split across line } \\
\text { because of length }\end{array}$ & $\begin{array}{l}\text { http://ceti.cse.ohiostate. } \\
\text { edu/kansei }\end{array}$ & (Yang 2010, p. 93) \\
\cline { 2 - 4 } & $\begin{array}{l}\text { http://www.acgrenoble. } \\
\text { fr/Partiels/shock.html }\end{array}$ & (Zajicek 2006, p.8) \\
\hline $\begin{array}{l}\text { URL with non-standard } \\
\text { capitalization }\end{array}$ & $\begin{array}{l}\text { Http://houstonradiohistory.blogspot.com2 } \\
\text { 007_06_01archive.html }\end{array}$ & (Liles 2008, p.48) \\
\hline $\begin{array}{l}\text { Text similar to URL } \\
\text { formatting }\end{array}$ & $\begin{array}{l}\text { Figure 0-2 the image produced by } \\
\text { HelloJAVA3Da.JAVA/HelloJAVA3Da.pl }\end{array}$ & $\begin{array}{l}\text { (Kandaswamy 2005, p. } \\
\text { 22) }\end{array}$ \\
\hline
\end{tabular}

$<$ Table-2: Sample URLs cited and referenced in the ETD text>

\section{Preparing the URL and ETD Dataset}

In analyzing the ETD URL dataset, the authors based the workflow on a similar set of steps used by Phillips and Murray (Phillips and Murray 2013) to analyze 4.5 million PDF documents from the End of Term 2008 project. Briefly this involved organizing the input dataset into a set of data samples, extracting additional information from samples, verifying samples as complete, indexing each sample and extracted field with Solr and finally querying the Solr system to compile statistics on different dimensions.

The UNT Digital Library houses the UNT Libraries' Theses and Dissertations Collection and provides a collection page at http://digital. library.unt.edu/explore/collections/UNTETD/. The digital library interface allows users to search and browse the items in this collection and presents developers with a number of application programming interfaces (API) including an Open Archives Initiative's' Protocol for Metadata Harvesting (OAI-PMH) repository endpoint. (UNT Libraries 2013) Using a Python OAI-PMH harvester, the authors harvested descriptive metadata and then processed it using a command-line tool based methodology in use by the UNT Libraries (Phillips 2013). Metadata extracted from the UNT ETD collection was used to create a subset of ETDs by date as well as supplement extracted URLs (mentioned below) with additional bibliographic information. For this research the authors were interested only in theses and 
dissertations, which were "born digital" and submitted electronically. At UNT this means items submitted from 1999 to the present. A total of 4,335 documents were extracted as candidates for further analysis.

The authors made use of the existing URL extraction API in the UNT Digital Library to extract URLs from each ETD. This extraction as described above includes URLs present in the body of the document as well as in the references or footnote sections. Each set of URLs is stored in a text file with a single $U R L$ instance per line. If a URL is mentioned more than one time in the document, it is repeated in the urls.txt file.

The authors wrote several Python scripts that combine information available in the ETDs metadata records with information extracted from the URL extraction API for each item in the dataset. As processing of the dataset was carried out it became evident that several methods of data cleaning were needed in order to analyze the dataset and remove noise resulting from the extraction process. For example, the authors normalized case in domain names, canonicalized URLs to a standard format and finally extracted subparts of each URL that could be used for metrics in the later research.

The output of several processing steps was used to clean URL strings for more consistent processing or to extract various pieces of information that would be aggregated in different ways when the data was indexed later in the process.

Actions included:

Unquoting each URL - (ex., convert \%20 to a space character)

Lower casing the incoming URLs domain names

Dividing each URL into subparts: protocol, domain, path, port etc.

Extracting domain, creating "domain surt"

Extracting top-level domains

Extract second level subdomains

If a URL failed any of the checks or data cleaning processes the authors considered it "noise" and excluded it from the data set. There are many reasons that these URLs may be malformed, incorrectly notated, or parsed incorrectly from the ETD text, as explained above. The goal of the cleaning and transforming steps was to provide a clean set of data to use in the subsequent indexing and querying portions of the research.

\section{Indexing the Dataset}

Nineteen data elements were extracted from each ETD sample and serialized as JSON files. The data elements included fields extracted from the metadata, and URL files as well as data calculated from processing and cleaning the URLs associated with each document. The extracted JSON data files were indexed using the Solr search system. This search system provided the ability to query the dataset using the data elements, as well as the ability to aggregate and generate statistics for various metrics of interest. 
The data elements that were extracted from each ETD sample files are listed below in alphabetical order:

- Author

- Date

- Degree Department

- Degree Grantor

- Degree Level

- Domains

- Domain SURTs

- Record Id

- Second Level Subdomains

- Top-level Domain
- Unique Domain Count

- Unique Domains

- Unique Second Level Subdomain Count

- Unique Top-level Domain Count

- Unique URLs

- UNTL FileSets

- URL Count

- URLS

- Year

\section{Query Formulation}

After indexing the dataset, the authors used the Solr search system to aggregate and generate statistics across the ETD dataset. The Solr system allowed the researchers to conduct an exploratory examination of the dataset, which supplemented previously formulated dataset queries. These queries utilized data present in each ETD sample and are presented in the findings listed below.

\section{Findings}

Key findings from the analysis of query response data from the Solr system are discussed in two categories. These are: UNT ETD dataset-wide URL analysis, and time-based URL analysis.

\section{ETD Dataset URL Analysis}

As can be seen from Table-3, the UNT ETD dataset contained 4,335 documents. Of these, 2,713 documents or $62 \%$ contained at least one URL.

\begin{tabular}{|l|l|l|l|}
\hline Total \# of ETDs & $\begin{array}{l}\text { \# of ETDs without } \\
\text { URLs }\end{array}$ & \# of ETDs with URLs & $\begin{array}{l}\% \text { of ETDs that } \\
\text { contain URLs }\end{array}$ \\
\hline 4,335 & 1,622 & 2,713 & $62.6 \%$ \\
\hline
\end{tabular}

$<$ Table-3: Total number of UNT's ETDs with and without URLs>

The UNT ETD dataset was divided into two levels by academic degrees, the doctoral level contained dissertations, and the master's level contained theses as well as papers associated with projects conducted in lieu of theses. The breakdown of ETDs into these two categories and the number of documents with and without URLs are presented in the table below. 


\begin{tabular}{|l|l|l|l|l|}
\hline Degree Level & $\begin{array}{l}\text { Total \# of } \\
\text { Documents }\end{array}$ & $\begin{array}{l}\text { \# of Documents } \\
\text { without URLs }\end{array}$ & $\begin{array}{l}\text { \# of Documents } \\
\text { with URLs }\end{array}$ & $\begin{array}{l}\text { \% of ETDs that } \\
\text { contain URLs }\end{array}$ \\
\hline Doctoral Level & 2,347 & 745 & 1,602 & $68.2 \%$ \\
\hline Master's Level & 1,988 & 877 & 1,111 & $55.8 \%$ \\
\hline
\end{tabular}

$<$ Table-4: UNT ETDs by Degree Levels>

Calculated as the sum of the number of URLs in each of the ETDs, the total number of URLs present in the UNT ETD dataset was 34,821. When duplicate URLs were removed, the dataset contained 26,683 unique URLs.

The authors were interested in the average number of URLs per document in the dataset, which was calculated to be 8.03 with a standard deviation of 21.6. These numbers represent documents, which contained from 0 to 809 URLs each. Removing the documents that did not contain URLS and recomputing the average changed it to 12.83 URLs per document with a standard deviation of 26.19 .

The table below shows a breakdown of several ranges of URLs per document.

\begin{tabular}{|l|l|l|l|}
\hline URL Range & \# of ETDs & \% of ETDs & Cumulative \% \\
\hline 0 & 1,622 & $37.42 \%$ & $37.42 \%$ \\
\hline 1 & 399 & $9.20 \%$ & $46.62 \%$ \\
\hline $2-9$ & 1,292 & $29.80 \%$ & $76.42 \%$ \\
\hline $10-30$ & 769 & $17.74 \%$ & $94.16 \%$ \\
\hline $31+$ & 253 & $5.84 \%$ & $100.00 \%$ \\
\hline
\end{tabular}

$<$ Table-5: UNT ETDs breakdown of several ranges of URLs per document>

The two degree levels of documents in the dataset exhibited small variations from the overall average number of URLs per document when their averages were calculated based on the number of documents that contain at least one URL. As depicted in Table 6 below, the standard deviation differed substantially between the two and suggests that doctoral level publications had a wider range of URL inclusion than master's level documents. 


\begin{tabular}{|l|l|l|l|}
\hline Degree Level & $\begin{array}{l}\text { \# of Documents with } \\
\text { URLs }\end{array}$ & $\begin{array}{l}\text { Average \# of URLs } \\
\text { per Document }\end{array}$ & Standard Deviation \\
\hline Doctoral & 1,602 & 14.02 & 30.72 \\
\hline Masters & 1,111 & 11.12 & 17.59 \\
\hline All Documents & 2,713 & 12.83 & 26.19 \\
\hline
\end{tabular}

<Table-6: Average number of URLs by degree levels>

URLs in each ETD record were deconstructed into their subparts and then indexed as four additional fields. These subparts included domain name, top-level domain, second level subdomain, and a Sort-friendly URI Reordering Transform (SURT) version of the domain name. For example, the transformation of the URL http://plants.usda.gov/java/profile?symbol=ALPH into its subparts is shown in the table below:

\begin{tabular}{|l|l|}
\hline URL & http://plants.usda.gov/java/profile?symbol=ALPH \\
\hline Domain & plants.usda.gov \\
\hline Top-Level Domain & gov \\
\hline Second Level Subdomain & usda.gov \\
\hline Domain Surt & gov.usda.plants \\
\hline
\end{tabular}

$<$ Table-7: A URL deconstructed into its subparts>

Deconstructing the URLs into their subparts and indexing them makes it possible to show the most referenced top-level domains; the most referenced second level subdomains or domain names. Limiting a full domain name to just its second level subdomain can be helpful because of wide variation in the number of subdomains that may occur within a given domain. For example, there were 97 different domain names that were themselves subdomains for unt.edu in the dataset. By extracting the second level subdomain from each URL, all domain names can be grouped based on these extracted values. Being able to group a URL or domain name into categories based on second level subdomain for analysis can be helpful for a higher level analysis of where the ETDs are linking. Below, Table-8 shows the ten most common top-level domains, and the number and percentage of documents that contain at least one URL reference to that top-level domain. 


\begin{tabular}{|l|l|l|}
\hline Top-level Domain & \# of documents & \% of documents with URLs \\
\hline com & 1,814 & $66.86 \%$ \\
\hline org & 1,579 & $58.20 \%$ \\
\hline edu & 1,212 & $44.67 \%$ \\
\hline gov & 1,084 & $39.96 \%$ \\
\hline net & 445 & $16.40 \%$ \\
\hline us & 361 & $13.31 \%$ \\
\hline uk & 269 & $9.92 \%$ \\
\hline ca & 184 & $6.78 \%$ \\
\hline au & 112 & $4.13 \%$ \\
\hline de & 100 & $3.69 \%$ \\
\hline
\end{tabular}

<Table-8: Top-level domain URL references>

Below, Table-9 presents the ten most referenced second level subdomains based on the number of documents along with the percentage of the total number of documents that contained at least one URL.

\begin{tabular}{|l|l|l|}
\hline Second level subdomain & \# of documents & \% of documents with URLs \\
\hline ed.gov & 295 & $10.87 \%$ \\
\hline state.tx.us & 274 & $10.10 \%$ \\
\hline unt.edu & 233 & $8.59 \%$ \\
\hline census.gov & 185 & $6.82 \%$ \\
\hline cdc.gov & 128 & $4.72 \%$ \\
\hline wikipedia.org & 96 & $3.54 \%$ \\
\hline nih.gov & 84 & $3.10 \%$ \\
\hline utexas.edu & 80 & $2.95 \%$ \\
\hline microsoft.com & 75 & $2.76 \%$ \\
\hline
\end{tabular}




\begin{tabular}{|l|l|l|}
\hline nytimes.com & 71 & $2.62 \%$ \\
\hline
\end{tabular}

$<$ Table-9: Ten most referenced second level subdomains>

A final set of metrics related to the average number of values for the different URL subparts in the ETD dataset is presented in Table-10. The table provides averages based on the total number of documents in the dataset as well as just the number of documents that contained at least one URL. Finally the data has been presented split into master's level and doctoral level in addition to numbers for the repository as a whole.

\begin{tabular}{|c|c|c|c|c|c|c|c|c|c|c|c|}
\hline 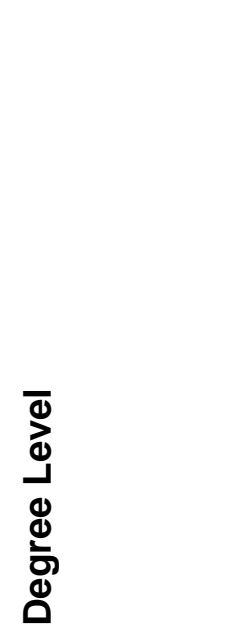 & 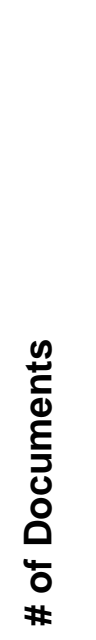 & 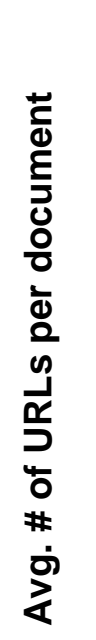 & 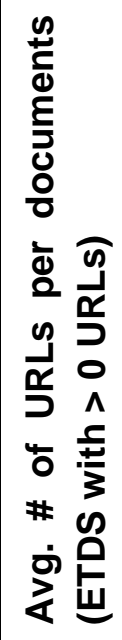 & 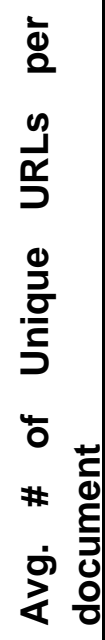 & 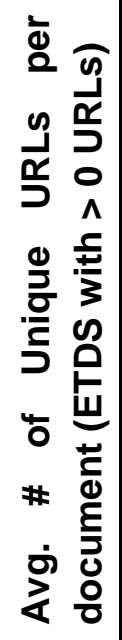 & 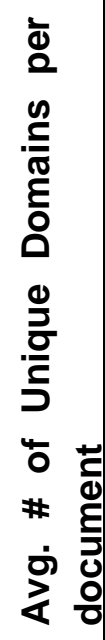 & 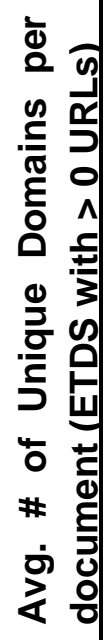 & 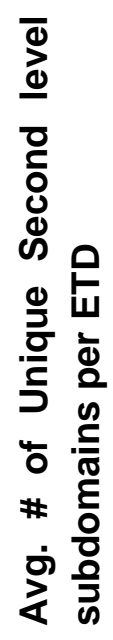 & 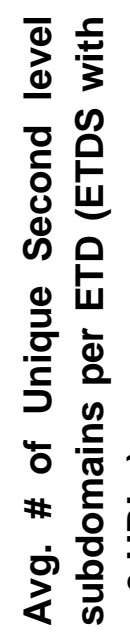 & 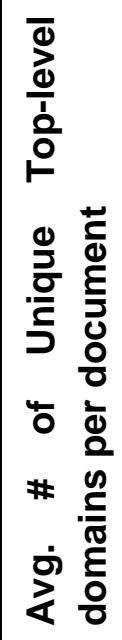 & 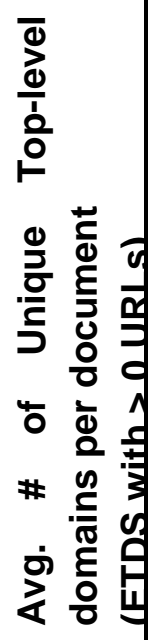 \\
\hline $\begin{array}{l}\text { Doctoral } \\
\text { Level }\end{array}$ & $\begin{array}{l}2,34 \\
7\end{array}$ & 9.57 & $\begin{array}{l}14.0 \\
2\end{array}$ & 7.96 & $\begin{array}{l}11.6 \\
6\end{array}$ & 6.29 & 9.21 & 5.94 & 8.71 & 2.29 & 3.36 \\
\hline $\begin{array}{l}\text { Master's } \\
\text { Level }\end{array}$ & $\begin{array}{l}1,98 \\
8\end{array}$ & 6.21 & $\begin{array}{l}11.1 \\
2\end{array}$ & 5.05 & 9.04 & 3.95 & 7.07 & 3.78 & 6.77 & 1.59 & 2.85 \\
\hline $\begin{array}{l}\text { All } \\
\text { Documents }\end{array}$ & $\begin{array}{l}4,33 \\
5\end{array}$ & 8.03 & $\begin{array}{l}12.8 \\
3\end{array}$ & 6.62 & $\begin{array}{l}10.5 \\
8\end{array}$ & 5.21 & 8.33 & 4.95 & 7.91 & 1.97 & 3.15 \\
\hline
\end{tabular}

$<$ Table-10: The average number of URLs per document>

\section{Time-based URL Analysis}

In addition to collection-specific numbers related to URL usage in the UNT ETD collection, the authors were interested in finding if the number of ETDs that contained URLs has changed over the past decade. The dataset as prepared makes it possible to show the number of documents that contained URLs at both the semester level and the year level. The data aggregated at the year level does a good job of demonstrating the growth in the number of ETDs that contain URLs over the past fourteen years at UNT. 


\begin{tabular}{|l|l|l|l|}
\hline Year & \# of ETDs & \# of ETDs with URLs & $\begin{array}{l}\% \text { of ETDs with } \\
\text { URLs }\end{array}$ \\
\hline 1999 & 120 & 28 & $23.33 \%$ \\
\hline 2000 & 315 & 127 & $40.32 \%$ \\
\hline 2001 & 290 & 116 & $40.00 \%$ \\
\hline 2002 & 298 & 146 & $48.99 \%$ \\
\hline 2003 & 328 & 198 & $60.37 \%$ \\
\hline 2004 & 304 & 181 & $59.54 \%$ \\
\hline 2005 & 284 & 199 & $70.07 \%$ \\
\hline 2006 & 326 & 235 & $72.09 \%$ \\
\hline 2007 & 349 & 258 & $73.93 \%$ \\
\hline 2008 & 336 & 242 & $72.02 \%$ \\
\hline 2009 & 311 & $132^{*}$ & $42.44 \%{ }^{*}$ \\
\hline 2010 & 366 & 286 & $78.14 \%$ \\
\hline 2011 & 418 & 335 & $80.14 \%$ \\
\hline 2012 & 290 & 230 & $79.31 \%$ \\
\hline
\end{tabular}

*Note: 2009 presented a lower than expected percentage of documents with URLs and the authors did not fully investigate the cause of this drop.

<Table-11: Longitudinal data for number of ETDs with URLs>

With the exception of a single year (2009), the number of ETDs containing URLs (Table-11) showed considerable growth over the past fourteen years, from about $23 \%$ in 1999 , to more than $80 \%$ in 2011.

The average number of URLs per document and the standard deviation is another helpful yet less dramatic way to see this change over time (see Table-12).

\begin{tabular}{|l|l|l|l|}
\hline Year & \# of ETDs with URLs & Avg. \# of URLs per ETD & Standard Deviation \\
\hline 1999 & 28 & 6.0 & 8.2 \\
\hline
\end{tabular}




\begin{tabular}{|l|l|l|l|}
\hline 2000 & 127 & 9.4 & 23.0 \\
\hline 2001 & 116 & 10.4 & 17.1 \\
\hline 2002 & 146 & 10.3 & 18.5 \\
\hline 2003 & 198 & 10.5 & 13.8 \\
\hline 2004 & 181 & 11.5 & 22.5 \\
\hline 2005 & 199 & 16.9 & 58.9 \\
\hline 2006 & 235 & 13.3 & 21.1 \\
\hline 2007 & 258 & 12.0 & 15.5 \\
\hline 2008 & 242 & 13.7 & 37.1 \\
\hline 2009 & 132 & 14.9 & 24.8 \\
\hline 2010 & 286 & 13.5 & 20.1 \\
\hline 2011 & 335 & 14.1 & 18.3 \\
\hline 2012 & 230 & 13.7 & 18.4 \\
\hline
\end{tabular}

$<$ Table-12: Average number of URLs per ETD by year>

The authors divided the yearly counts of ETDs with and without URLs into the categories of master's level and doctoral level in order to understand trends between the two academic degree levels over the past fourteen years. The result of this analysis can be seen in Table- 13 below.

\begin{tabular}{|l|l|l|l|l|l|l|l|l|}
\hline Year & $\begin{array}{l}\text { Total \# } \\
\text { of ETD }\end{array}$ & $\begin{array}{l}\text { Doctora } \\
\text { I ETDs }\end{array}$ & $\begin{array}{l}\text { Mast } \\
\text { er's } \\
\text { ETDs }\end{array}$ & $\begin{array}{l}\text { Doctora } \\
\text { I ETDs } \\
\text { with } \\
\text { URLs }\end{array}$ & $\begin{array}{l}\text { \% of } \\
\text { Doctora } \\
\text { I ETDs } \\
\text { with } \\
\text { URLs }\end{array}$ & $\begin{array}{l}\text { Master' } \\
\text { s ETDs } \\
\text { with } \\
\text { URLs }\end{array}$ & $\begin{array}{l}\text { of of } \\
\text { Master' } \\
\text { sTDs } \\
\text { with } \\
\text { URLs }\end{array}$ & $\begin{array}{l}\text { Doctoral } \\
\text { Level to } \\
\text { Masters } \\
\text { Level \% } \\
\text { Difference }\end{array}$ \\
\hline 1999 & 120 & 69 & 51 & 17 & $24.6 \%$ & 11 & $21.6 \%$ & $3.0 \%$ \\
\hline 2000 & 315 & 182 & 133 & 82 & $45.1 \%$ & 45 & $54.9 \%$ & $-9.8 \%$ \\
\hline 2001 & 290 & 147 & 143 & 69 & $46.9 \%$ & 47 & $32.9 \%$ & $14.0 \%$ \\
\hline 2002 & 298 & 144 & 154 & 78 & $54.2 \%$ & 68 & $44.2 \%$ & $10 \%$ \\
\hline 2003 & 328 & 165 & 163 & 107 & $64.8 \%$ & 91 & $55.8 \%$ & $9 \%$ \\
\hline
\end{tabular}




\begin{tabular}{|l|l|l|l|l|l|l|l|l|}
\hline 2004 & 304 & 140 & 164 & 100 & $71.4 \%$ & 81 & $49.4 \%$ & $22 \%$ \\
\hline 2005 & 284 & 144 & 140 & 119 & $82.6 \%$ & 80 & $57.1 \%$ & $25.5 \%$ \\
\hline 2006 & 326 & 183 & 143 & 139 & $76.0 \%$ & 96 & $67.1 \%$ & $8.9 \%$ \\
\hline 2007 & 349 & 197 & 152 & 158 & $86.3 \%$ & 100 & $65.8 \%$ & $20.5 \%$ \\
\hline 2008 & 336 & 208 & 128 & 158 & $76.0 \%$ & 84 & $65.6 \%$ & $10.4 \%$ \\
\hline 2009 & 311 & 177 & 134 & 81 & $45.8 \%$ & 51 & $38.1 \%$ & $7.7 \%$ \\
\hline 2010 & 366 & 215 & 151 & 174 & $81.0 \%$ & 112 & $74.2 \%$ & $6.8 \%$ \\
\hline 2011 & 418 & 226 & 192 & 192 & $85.0 \%$ & 143 & $74.4 \%$ & $10.6 \%$ \\
\hline 2012 & 290 & 150 & 140 & 128 & $85.3 \%$ & 102 & $72.9 \%$ & $12.4 \%$ \\
\hline
\end{tabular}

$<$ Table-13: Number of ETDs with URLs by degree level and year>

Finally the five most referenced top-level domains for each year and their associated document counts were compiled in Table-14.

\begin{tabular}{|l|l|l|l|l|l|l|l|l|l|l|l|}
\hline Year & $\begin{array}{c}\text { \# of } \\
\text { ETDs } \\
\text { with } \\
\text { URLs }\end{array}$ &. com & $\%$.com &. org & $\%$. org &. .du & $\%$. edu &. gov & $\% . g o v$ &. net & $\% . n e t$ \\
\hline 1999 & 28 & 14 & $42.9 \%$ & 9 & $32.1 \%$ & 11 & $39.3 \%$ & 4 & $14.3 \%$ & 4 & $\begin{array}{l}14.3 \\
\%\end{array}$ \\
\hline 2000 & 127 & 66 & $52.0 \%$ & 70 & $55.1 \%$ & 53 & $41.7 \%$ & 41 & $32.3 \%$ & 19 & $\begin{array}{l}15.0 \\
\%\end{array}$ \\
\hline 2001 & 116 & 63 & $54.3 \%$ & 67 & $57.8 \%$ & 57 & $49.1 \%$ & 39 & $33.6 \%$ & 20 & $\begin{array}{l}17.2 \\
\%\end{array}$ \\
\hline 2002 & 146 & 102 & $69.9 \%$ & 73 & $50.0 \%$ & 62 & $42.5 \%$ & 47 & $32.2 \%$ & 18 & $\begin{array}{l}12.3 \\
\%\end{array}$ \\
\hline 2003 & 198 & 133 & $67.2 \%$ & 96 & $48.5 \%$ & 84 & $42.4 \%$ & 70 & $35.4 \%$ & 24 & $\begin{array}{l}12.1 \\
\%\end{array}$ \\
\hline 2004 & 181 & 122 & $67.4 \%$ & 89 & $49.2 \%$ & 84 & $46.4 \%$ & 66 & $36.5 \%$ & 23 & $\begin{array}{l}12.7 \\
\%\end{array}$ \\
\hline
\end{tabular}




\begin{tabular}{|l|l|l|l|l|l|l|l|l|l|l|l|}
\hline 2005 & 199 & 141 & $70.9 \%$ & 112 & $56.3 \%$ & 100 & $50.3 \%$ & 83 & $41.7 \%$ & 43 & $\begin{array}{l}21.6 \\
\%\end{array}$ \\
\hline 2006 & 235 & 155 & $66.0 \%$ & 143 & $60.9 \%$ & 116 & $49.4 \%$ & 98 & $41.7 \%$ & 40 & $\begin{array}{l}17.0 \\
\%\end{array}$ \\
\hline 2007 & 258 & 182 & $70.5 \%$ & 157 & $60.9 \%$ & 122 & $47.3 \%$ & 116 & $45.0 \%$ & 35 & $\begin{array}{l}16.6 \\
\%\end{array}$ \\
\hline 2008 & 242 & 166 & $68.6 \%$ & 140 & $57.9 \%$ & 99 & $41.0 \%$ & 91 & $37.6 \%$ & 40 & $\begin{array}{l}16.5 \\
\%\end{array}$ \\
\hline 2009 & 132 & 87 & $65.9 \%$ & 83 & $62.9 \%$ & 69 & $52.3 \%$ & 50 & $37.9 \%$ & 25 & $\begin{array}{l}19.0 \\
\%\end{array}$ \\
\hline 2010 & 286 & 199 & $69.6 \%$ & 170 & $59.4 \%$ & 127 & $44.4 \%$ & 129 & $45.1 \%$ & 50 & $\begin{array}{l}17.5 \\
\%\end{array}$ \\
\hline 2012 & 230 & 153 & $66.5 \%$ & 155 & $67.4 \%$ & 94 & $40.9 \%$ & 104 & $45.2 \%$ & 38 & $\begin{array}{l}16.5 \\
\%\end{array}$ \\
\hline
\end{tabular}

Note: Shading denotes the top-level domain with the highest ETD count for that year.

$<$ Table-14: Number of ETDs with URLs by domain names>

\section{Discussion}

The research conducted by the authors clearly demonstrated that URLs are being included into ETDs in the majority of cases: $62 \%$ of the publications analyzed in this work included URLs. This percentage changed slightly when divided between doctoral level publications at $68.2 \%$ and master's level at 55.8\%.

A clear increase in the percentage of ETDs that include URLs was present in the UNT dataset from $23 \%$ in 1999 to almost $80 \%$ in 2012 . Across the years, doctoral level students had a higher practice of including URLs in their dissertations than master's level students did in their theses. In fact this was true for all but one year when in 2000 , there were more theses than dissertations with URLs referenced.

An interesting finding of the small amount of content investigation done in this paper is that even though the .gov domain is typically the fourth most referenced top-level domain in these publications, it accounts for nearly half of the top ten most referenced domains across these 
publications. A further investigation at the domain or subdomain level could reveal additional patterns that may show more content-based information about the URL references.

\section{Future Work}

The authors feel that a deeper investigation into the scope of the target URLs across an entire ETD corpus could provide a better understanding of the content-based URL linking patterns that may be present in the collection. Additionally an investigation into how specific disciplines or subject areas are referencing URLs in their ETDs would be helpful in identifying particularly high areas of URL linking versus lower levels.

An analysis of URL inclusion in ETDs across institutions and even nations would make a logical follow-on investigation that would show if higher-level trends exist in ETDs. Adopting the recommendations by (Sanderson et al., 2011) that repositories create machine interfaces that allow for programmatic access to the URLs embedded in repository content could facilitate this work.

Finally a further investigation into URL extraction from text would be beneficial to the ETD community in several ways. First it would allow libraries to extract URLs not only from born digital ETDs but also from theses and dissertations that are being retrospectively digitized in institutions that have not had longstanding ETD policies. Second it would allow for investigation into ways of normalizing or completing malformed URLs that may provide for better analysis of content referenced and its availability in Web archives.

\section{Conclusion}

As the Web continues to gain importance in lives of people around the world, its importance as research subject and vehicle for scholarly communication will continue to grow. Graduate students at the University of North Texas are increasingly using URLs in their theses and dissertations, a trend that is likely to increase into the future. The URLs referenced in a large corpus of ETDs may be present interesting insight into the subjects, disciplines and patterns in these documents, which warrants further investigation. Finally the increase of URL inclusion in ETDs does provide an opportunity for libraries and archives responsible for the curation of these resources to consider collecting and preserving the resources and scholarly context linked to by these documents by harvesting and curating these Web resources locally. This research provides

a preliminary framework for technical methods appropriate for approaching future analysis of the data. 


\section{References}

Alemneh, D. G. (2009), "An Examination of the Adoption of Preservation Metadata in Cultural Heritage Institutions: An Exploratory Study Using Diffusion of Innovations Theory," (Doctoral Dissertations, University of North Texas), available at: http://digital.library.unt.edu/ark:/67531/metadc9937/ (accessed 19 August 2013).

Dondlinger, M.J. (2009), "The Global Village Playground: A qualitative case study of designing an ARG as a capstone learning experience", (Doctoral Dissertations, University of North Texas), available at: http://digital.library.unt.edu/ark:/67531/metadc10995/ (accessed 19 August 2013).

Horton, J.C. (2002), "The External Conflict of Modern War Correspondents: Technology's Inevitable Impact on the Extinction of Nostalgic Combat Reporting", (Master's thesis, University of North Texas), available at: http://digital.library.unt.edu/ark:/67531/metadc3247/ (accessed 19 August 2013).

Kandaswamy, B. (2005), "Planning techniques for agent based 3D animations", (Master's thesis, University of North Texas), available at: http://digital.library.unt.edu/ark:/67531/metadc4958/ (accessed 19 August 2013).

Liles, D.M. (2008), "Wyatt Cephas Hedrick: Builder of Cities”, (Master's thesis, University of North Texas), available at: http://digital.library.unt.edu/ark:/67531/metadc6084/ (accessed 19 August 2013).

Phillips, M. (2013), "Metadata Analysis at the Command Line", Code4Lib Journal, Vol. 19, available at: http://journal.code4lib.org/articles/7818 (accessed 19 August 2013).

Phillips, M. and Murray, K. (2013), "Improving Access to Web Archives through innovative Analysis of PDF Content.", in Archiving-2013 Conference proceedings in Washington D.C., USA, 2013, Society for Imaging Science and Technology, pp. 186-192.

Salaheldeen, H. and Nelson, M. (2013), "Reading the Correct History? Modeling Temporal Intention in Resource Sharing", paper presented at the Joint Conference on Digital Libraries, (JCDL) 22 -26 July, Indianapolis, Indiana, USA, available at: http://arxiv.org/abs/1307.4063 (accessed 19 August 2013).

Sanderson, R., Phillips, M. E., \& Van de Sompel, H. (2011), "Analyzing the persistence of referenced web resources with Memento", paper presented at the Sixth Annual International Conference on Open Repositories, Austin, TX, USA, available at: http://digital.library.unt.edu/ark:/67531/metadc39318/ (accessed 19 August 2013).

Yang, J. (2010), "Design and Implementation of Large-Scale Wireless Sensor Networks for Environmental Monitoring Applications", (Doctoral Dissertations, University of North Texas), available at: http://digital.library.unt.edu/ark:/67531/metadc28493/ (accessed 19 August 2013). 
Zajicek, D.J. (2006). "A Rhetorical Guide to Ebb”, (Master's thesis, University of North Texas), available at: http://digital.library.unt.edu/ark:/67531/metadc5236/ (accessed 19 August 2013).

\section{Technical References}

Elkins, M. (n.d.), "urlview. Linux Man Pages", available at: http://www.linuxmanpages.com/man1/urlview.1.php\#lbAH (accessed 19 August 2013).

Internet Archive. (2012a). "ExtractorUniversal (Heritrix 3 3.1.1 API), Application Programming Interface (API) for Heritrix)", available at: http://builds.archive.org:8080/javadoc/heritrix-3.1.1/ (accessed 19 August 2013).

Internet Archive. (2012b), "PDFParser (Heritrix 3 3.1.1 API). Application Programming Interface (API) for Heritrix", available at: http://builds.archive.org:8080/javadoc/heritrix-3.1.1/ (accessed 19 August 2013).

Open Archives Initiative (2002), "Protocol for Metadata Harvesting (OAI--PMH)", available at: http://www.openarchives.org/pmh/ (accessed 19 August 2013).

UNT Libraries (2013), "APIs for UNT Theses and Dissertations", available at: http://digital.library.unt.edu/explore/collections/UNTETD/api/ (accessed 19 August 2013). 


\section{Biographical Details}

- Mark Phillips is the Assistant Dean for Digital Libraries at the University of North Texas Libraries. Phillips became the digital projects lab manager for the UNT Libraries after he received his master's degree, and then became head of the Digital Projects Unit. Since 2010, he has served as Assistant Dean for Digital Libraries, overseeing the User Interfaces Unit and the Digital Projects Unit, which contains the Digital Curation Team, the Digital Projects Lab, the Digital Newspaper Team, and the Software Development Team. $\mathrm{He}$ is responsible for the design and implementation of the access and preservation systems used by The Portal to Texas History, UNT Digital Library and The Gateway to Oklahoma History. His research interests include: Web archiving, digital library infrastructure, metadata quality analysis, and digital production workflows.

- Daniel Gelaw Alemneh is the Digital Curation coordinator for Digital Libraries at the University of North Texas Libraries, where he manages and coordinates ETDs related activities. His work and research revolves around digital libraries in general and his ETD related involvements includes the IMLS ETD Lifecycle Management Project where he coordinates the steering committee work on the Overview of PREMIS Metadata document. Daniel is also an Adjunct Faculty at UNT's College of Information where he teaches indexing, abstracting, and information retrieval courses.

- Brenda Reyes Ayala is a doctoral candidate in the University of North Texas College of Inforation and a research assistant in the UNT Libraries Digital Projects Unit where she is a member of the Web Archiving Team. Her research interests include automated and manual quality control workflows and techniques in Web archives. 